\title{
Mixed Convection of Heat Transfer around Rotating Cylinders inside Enclosure Filled with Nano Fluid
}

\author{
${ }^{1}$ Farhan A.I., ${ }^{2}$ Ziad M.Al-Makhyoul \\ ${ }^{1,2}$ Department of Mechanical Engineering, University of Mosul, Iraq \\ *Corresponding Author's Email: ziadalmakhyoul@uomosul.edu.iq
}

\begin{abstract}
Mixed convection of heat transfer in 2D-square enclosure with an inner two rotating solid circular cylinder had been investigated numerically, the domain between the enclosure walls and cylinders is filled with (Cu-Water) nano fluid. For numerical computational, the dimensionless governing equations were modeled and formulated based on the Galerkin Finite Element Methods. All walls of the enclosure were insulated while the right cylinder was kept at constant hot temperature and the other left cylinder was kept at constant cold temperature. The current study examines the effect of the cylinders angular rotational speed between $(0$ and -10000$)$, cylinders diameter $(0.2,0.3$, and 0.4$)$, Richardson number (0.1 and 10), and the volume fraction of the nano particle ( 0 to 0.6$)$. The results have been shown in term of isotherm lines, stream function, average Nusselt number, and offered graphically. The results showed that the temperature gradient , intensity of flow and average Nusselt number increases with increase of angular rotational speed, the diameter, and the volume fraction of the nanoparticle whereas it decreases with an increase in Richardson number. The enhancement of the average Nusselt number increase with increase of rotating speed, concentration of nanoparticle and cylinder diameter with ratio of $(\mathbf{7 5 . 1 7 \%}),(3.37 \%)$ and $(\mathbf{7 3 . 2 5 \%})$ respectively. While the average Nusselt number decreased with increase in Richardson number with ratio of $(13.37 \%)$.
\end{abstract}

Keywords: Mixed convection; Nanofluid; Numerical simulation; Rotating cylinder; Enclosure.

\begin{tabular}{|c|l|c|l|}
\hline \multicolumn{3}{|c|}{ Nomenclature } \\
\hline $\mathrm{Cp}$ & Specific heat & \multicolumn{2}{|c|}{ Greek characters } \\
\hline $\mathrm{D}=\mathrm{D}_{1}=\mathrm{D}_{2}$ & Diameter of the cylinder & $\Psi$ & Absolute stream function \\
\hline $\mathrm{G}$ & Gravitational acceleration & $\emptyset$ & Solid volume fraction \\
\hline$G r$ & Grashof number & $\theta$ & Dimensionless temperature \\
\hline $\mathrm{H}$ & $\begin{array}{l}\text { Convection Heat Transfer } \\
\text { Coefficient }\end{array}$ & $\mathrm{M}$ & Dynamic viscosity \\
\hline $\mathrm{K}$ & Thermal conductivity & $\mathrm{A}$ & Thermal diffusivity \\
\hline $\mathrm{L}$ & Length of the enclosure & $\mathrm{B}$ & Thermal \\
& & & coefficient \\
\hline$\overline{N u}$ & Average Nusselt number & & \multicolumn{1}{|c|}{ Subscripts } \\
\hline $\mathrm{P}$ & Dimensionless pressure & $b f$ & Base fluid \\
\hline$P r$ & Prandtl number & $\mathrm{C}$ & Cold \\
\hline $\mathrm{R}$ & The radius of the cylinder & $\mathrm{H}$ & Hot \\
\hline$R a$ & Rayleigh number & $M a x$ & Max value \\
\hline$R e$ & Reynolds number & $n f$ & Nanofluid \\
\hline$R i$ & Richardson number & $p$ & Nanoparticles \\
\hline $\mathrm{T}$ & Dimensionless temperature & $\mathrm{S}$ & Surface \\
\hline $\mathrm{X}, \mathrm{y}, \mathrm{z}$ & Dimensional Velocity Component & & \\
\hline
\end{tabular}

\section{INTRODUCTION}

The phenomenon of heat transfer and fluid flow in mixed convection from rotating circular solid cylinder inside a square enclosure filled with fluid is a big problem for thermal engineering applications, such as rotating-tube heat exchangers, rotating shafts, drilling of oil wells, nuclear reactor fuel rods and steel suspension bridge cables [1].For the importance of these 
applications in our life, many researchers have studied mixed convection by replacing traditional heat carrier fluids with nano fluid. It consists of nano particles $\left(\mathrm{Ag}, \mathrm{Au}, \mathrm{Cu}, \mathrm{MgO}, \mathrm{SiO}_{2}, \mathrm{FeO}_{3}\right.$, and $\mathrm{TiO}_{2}$ ) sized from (1-100nm) suspended in base fluid like; (Water, ethylene, alcohol, oil, etc.). Nowadays, many researchers are interested in these new fluids, so they have studied different cases theoretically and experimentally due to its huge heat transfer capability compared to pure heat transfer fluid.

To enhance the heat transfer of natural convection by using nanofluid and porous media inside horizontal and inclination cavity presented by $[2,3,4,5,6]$, the results have shown that the average Nusselt number has increased with the increase ofthe concentration of nanoparticle and Rayleigh number. An analytical study with one active inner rotating cylinder inside square enclosure implemented by Roslan et. al [7].Angular rotational velocity, concentration, and diameter of the cylinder was an inquiry and it was observed that slowly rotating cylinder with mild diameter was effective for the enhancement of heat transfer. In the numerical study by Chatterjee et.al [8]. It was noted that the heat transfer greatly depended on the rotational speed of the cylinder, mixed convection strength, and nanoparticle concentration of the rotating circular cylinder inside the lid-driven cavity. Alsebery et.al [9]. Performed mixed convection of heated rotating inner cylinder filled with nanofluid in a square cavity when the nanoparticle load and Rayleigh number increased, it was found that the increase in the heat transfer with moderate angular velocity and small radius obtains the best heat transfer. In a numerical study performed by Majdi et. al [10]. On natural convection inner circular cylinder in parallelogram enclosure filled with nanofluid, they obtained enhancement in heat transfer during the vertical motion of the cylinder with an inclination of the enclosure. Park et. al[11]. Inquiry the free convection caused by a temperature variation between two hot circular cylinders inside cold square cavity walls, where the inner cylinders situated at various vertical centerline of the cavity for different range of Rayleigh number from $\left(10^{3}\right.$ to $\left.10^{6}\right)$, they observed that deployment of isotherms line and fluid flow recently arrive a steady state or change its state from stable to unsettled depending on cylinder position and Rayleigh number value. Selimefendigil and Oztop[12].

Investigated mixed convection heat transfer of ferrofluid effect inside a lid-driven cavity containing two rotating cylinders. They observed that the maximum heat transfer was reinforced with the ratio of angular velocity and cylinder diameter within the cavity in clockwise rotation compared to motionless cylinders. The effect of the two cylinders inside the enclosure filled vertically layered by fluid and porous media was studied analytically by Ismael et.al [13]. They noticed enhancement with an increase in cylinder radius in addition to Rayleigh number in the average heat transfer with horizontal movement of the two cylinders. Numerical simulation of the three-dimensional cavity containing two adiabatic rotating cylinders filled with nanofluid was presented by Selimefendigil and oztop[14]. Their results detected the rate of heat transfer enhancement with a high value of Rayleigh number concentration of nanoparticles and rotation direction within the average Nusselt number deterioration or enhancement. Porous media and nanofluid optimization inside cavity enhancement heat transfer with two rotating cylinders numerically were studied by Tahmasbi et. al[15]. It was found that, in the best condition, increases in the heat transfer was done by optimization of different Rayleigh and Richardson numbers and high concentration volume fraction.

\section{PROBLEM FORMULATION}

The problem depicted in the present study is mixed convection in a closed enclosure with two circular cylinders. Figure (1) shows the physical geometry of the 2D-enclosure with two cylinders in rotating placed in the center location filled with nanofluid. The size of the enclosure walls (length and height) is equal and symbolized as (L); the left cylinder is kept at constant cold temperature $\left(T_{c}\right)$, and the right cylinder is kept at constant hot temperature $\left(T_{h}\right)$, while all other walls of the enclosure are assumed to be isolated. The nanofluid consists of base fluid (Water) and nanoparticles material $(\mathrm{Cu})$. The cylinders rotate together with different angular velocities. The fluid flow domain and the properties of the heat transfer are assumed to be under steady-state conditions, laminar flow, and incompressible. The fluid is assumed to be Newtonian even with the highest concentration of solid nanoparticles. Besides, the thermophysical properties of the nanofluid are adopted constant except the density of the body force in terms of Y-Momentum Navier-Stokes equations which vary according to the Boussinesq approximation. The thermophysical properties of water and nanoparticles [16] are illustrated in Table 1. 


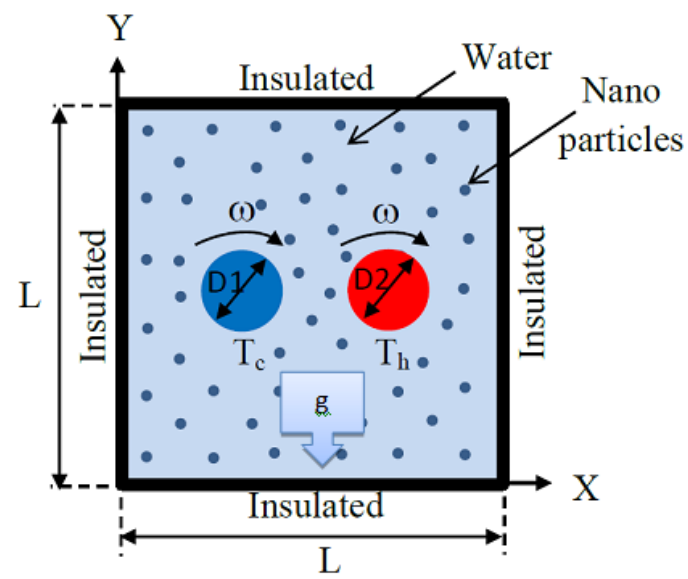

Figure (1): The physical geometry of enclosure

\section{MATHEMATICAL MODEL}

In this study, the numerical solution has been used to solve the governing equations of $2 \mathrm{D}$ coordinates. The continuity, momentum, and energy equations are given in [17] and can be represented as:

1-continuity equation

$$
\frac{\partial u}{\partial x}+\frac{\partial v}{\partial y}=0
$$

2-momentum equation

$$
\begin{aligned}
& \mathrm{u} \frac{\partial \mathrm{u}}{\partial \mathrm{x}}+\mathrm{v} \frac{\partial \mathrm{u}}{\partial \mathrm{y}}=-\frac{1}{\rho} \frac{\partial \mathrm{p}}{\partial \mathrm{x}}+\frac{\mu}{\rho}\left(\frac{\partial^{2} \mathrm{u}}{\partial \mathrm{x}^{2}}+\frac{\partial^{2} \mathrm{u}}{\partial \mathrm{y}^{2}}\right) \\
& \frac{\partial v}{\partial x}+v \frac{\partial v}{\partial y}=-\frac{1}{\rho} \frac{\partial p}{\partial x}+\frac{\mu}{\rho}\left(\frac{\partial^{2} v}{\partial x^{2}}+\frac{\partial^{2} v}{\partial y^{2}}\right)+\beta g\left(T-T_{c}\right)
\end{aligned}
$$

3-energy equation

$$
u \frac{\partial T}{\partial x}+v \frac{\partial T}{\partial y}=\frac{k}{\rho * C p}\left(\frac{\partial^{2} T}{\partial x^{2}}+\frac{\partial^{2} T}{\partial y^{2}}\right)
$$

The non-dimensional parameters are used to convert the above dimensional equations to non-dimensional equations as in [18] and can be written as:

$\left[X=\frac{x}{L}\right], Y=\frac{y}{L}, \quad U=\frac{u L}{\alpha}, \quad V=\frac{v L}{\alpha}, \Theta=\frac{T-T_{c}}{T_{h}-T_{c}}$,

$\operatorname{Pr}_{f}=\frac{v_{f}}{\alpha_{f}}, \quad \Omega=\frac{\omega L^{2}}{\alpha} \quad \alpha=\frac{K}{\rho C p}, \quad v=\frac{\mu}{\rho}, \quad R i=\frac{R a \times \operatorname{Pr}}{4 \Omega^{2} R^{4}}$

The non-dimensional formula of the equations (1) to (4) can be written as:

$$
\begin{gathered}
\frac{\partial \mathrm{U}}{\partial \mathrm{X}}+\frac{\partial \mathrm{V}}{\partial \mathrm{Y}}=0 \\
U \frac{\partial U}{\partial X}+V \frac{\partial U}{\partial Y}=-\frac{\partial P}{\partial X}+P r_{b f} \frac{\rho_{b f} \mu_{n f}}{\rho_{n f} \mu_{b f}}\left(\frac{\partial^{2} U}{\partial X^{2}}+\frac{\partial^{2} U}{\partial Y^{2}}\right) \\
U \frac{\partial V}{\partial X}+V \frac{\partial V}{\partial Y}=-\frac{\partial P}{\partial X}+P r_{b f} \frac{\rho_{b f} \mu_{n f}}{\rho_{n f} \mu_{b f}}\left(\frac{\partial^{2} V}{\partial X^{2}}+\frac{\partial^{2} V}{\partial Y^{2}}\right)+4 R i \Omega^{2} R^{4} \times \frac{\rho_{b f}}{\rho_{n f}}\left[1-\emptyset+\emptyset \frac{\rho_{p} \beta_{p}}{\rho_{b f} \beta_{b f}}\right] \theta
\end{gathered}
$$




$$
U \frac{\partial \theta}{\partial X}+V \frac{\partial \theta}{\partial Y}=\frac{k_{n f}(\rho C p)_{b f}}{k_{b f}(\rho C p)_{n f}}\left(\frac{\partial^{2} \theta}{\partial X^{2}}+\frac{\partial^{2} \theta}{\partial Y^{2}}\right)
$$

The relations of thermophysical proprieties for the nanofluid are described in the following models [19]- [23]: Nanofluid density:

$$
\rho_{n f}=(1-\varphi) \rho_{b f}+\varphi \rho_{p}
$$

Thermal expansion coefficient:

$$
\beta=-\frac{1}{\rho}\left(\frac{\partial p}{\partial T}\right)_{p}
$$

Dynamic viscosity:

$$
\frac{\mu_{n f}}{\mu_{b f}}=\frac{1}{(1-\emptyset)^{2.5}}
$$

Specific heat capacity:

$$
(\rho c p)_{n f}=(1-\varphi)(\rho c p)_{b f}+\varphi(\rho c p)_{p}
$$

Thermal conductivity:

$$
\frac{k_{n f}}{k_{b f}}=\frac{k_{p}+2 k_{b f}-2 \emptyset\left(k_{b f}-k_{p}\right)}{k_{p}+2 k_{b f}+2 \emptyset\left(k_{b f}-k_{p}\right)}
$$

Table 1. Thermophysical properties of water and nanoparticles

\begin{tabular}{|c|c|c|}
\hline Properties & Water & $\mathrm{Cu}$ \\
\hline$C_{p}(\mathrm{~J} / \mathrm{kg} . \mathrm{K})$ & 4179 & 383 \\
\hline$\rho\left(\mathrm{kg} / \mathrm{m}^{3}\right)$ & 997.1 & 8954 \\
\hline$\mu(\mathrm{Kg} / \mathrm{m})$ & 0.001003 & - \\
\hline$k(W / m . K)$ & 0.613 & 400 \\
\hline$\beta$ & $21 \times 10^{-5}$ & $1.67 \times 10^{-5}$ \\
\hline
\end{tabular}

It is possible to represent the motion of nanofluid in terms of stream function which comes from two-component of velocities $\mathrm{U}$ and V. The relationship between stream function and velocity components can be written as follows [24]:

$$
\frac{\partial^{2} \Psi}{\partial \mathrm{X}^{2}}+\frac{\partial^{2} \Psi}{\partial \mathrm{Y}^{2}}=\frac{\partial \mathrm{U}}{\partial \mathrm{Y}}-\frac{\partial \mathrm{V}}{\partial \mathrm{X}}
$$

The boundary conditions withnon-dimensional equations are formed as follows:

1. The right cylinder at constant hot temperature.

$$
\theta=1, U=\frac{\left(\mathrm{Y}-\mathrm{Y}_{0}\right)}{\mathrm{R}}=\Omega\left(\mathrm{Y}-\mathrm{Y}_{0}\right), \mathrm{V}=\frac{\left(\mathrm{X}_{0}-\mathrm{X}\right)}{\mathrm{R}}=\Omega\left(\mathrm{X}_{0}-\mathrm{X}\right)
$$

2. The left cylinder is at constant cold temperature.

$$
\theta=0, U=\frac{\left(Y-Y_{0}\right)}{R}=\Omega\left(Y-Y_{0}\right), V=\frac{\left(X_{0}-X\right)}{R}=\Omega\left(X_{0}-X\right)
$$

3. All other vertical and horizontal walls of the cavity are insulated.

$$
\theta=0, \frac{\partial \theta}{\partial n}=0, U=0, V=0
$$


Where $\frac{\partial \theta}{\partial n}$ is the mean of the changes in non-dimensional temperature to the normal direction on any surface.

Nusselt number is a dimensionless parameter referring to the ratio of convective heat transfer to conduction over any given fluid. The average $(\mathrm{Nu})$ on the hot surface cylinder could be expressed as [25] :

$$
\begin{gathered}
\mathrm{Nu}=\frac{\mathrm{hL}}{\mathrm{kb}_{\mathrm{bf}}} \\
\mathrm{h}=\frac{\mathrm{q}_{\mathrm{w}}}{\mathrm{T}_{\mathrm{h}}-\mathrm{T}_{\mathrm{c}}} \\
\mathrm{k}_{\mathrm{nf}}=\frac{\mathrm{q}_{\mathrm{w}}}{\partial \theta / \partial \mathrm{X}} \\
\mathrm{Nu}_{l}=-\left(\frac{\mathrm{k}_{\mathrm{nf}}}{\mathrm{k}_{\mathrm{bf}}}\right) \frac{\partial \theta}{\partial \mathrm{X}} \\
\overline{\mathrm{Nu}}=\int_{0}^{1}\left[-\left(\frac{\mathrm{k}_{\mathrm{nf}}}{\mathrm{k}_{\mathrm{bf}}}\right) \frac{\partial \theta}{\partial \mathrm{X}}\right] \mathrm{dY}
\end{gathered}
$$

\section{NUMERICAL PROCEDURE AND GRID TEST STUDY}

The group of governing non-dimensional equations (5)-(8) besides the suitable boundary conditions (15)-(17) presented in the mathematical model were solved by Galerkin weighted residual technique. The finite element method is used for the computational domain and the domain is divided into sub domains, these done by using computational fluid dynamics (CFD) technique through a computer simulation code (COMSOL Multiphysics 5.6).This simulation code is a modren code used numerical algorithms to analyze questions of geometrical forms and non-geometrical forms it also contains presentation style to show the results in terms by isotherms line, stream function, average Nu inside enclosure [26]. Finally, to reduce the arithmetic error of the current study the idea adopted is when the error of convergence criterion of every single variable reaches targeted $10^{-6}$. The triangular mesh element is chosen for this research with nanofluid as shown in Figure (2).

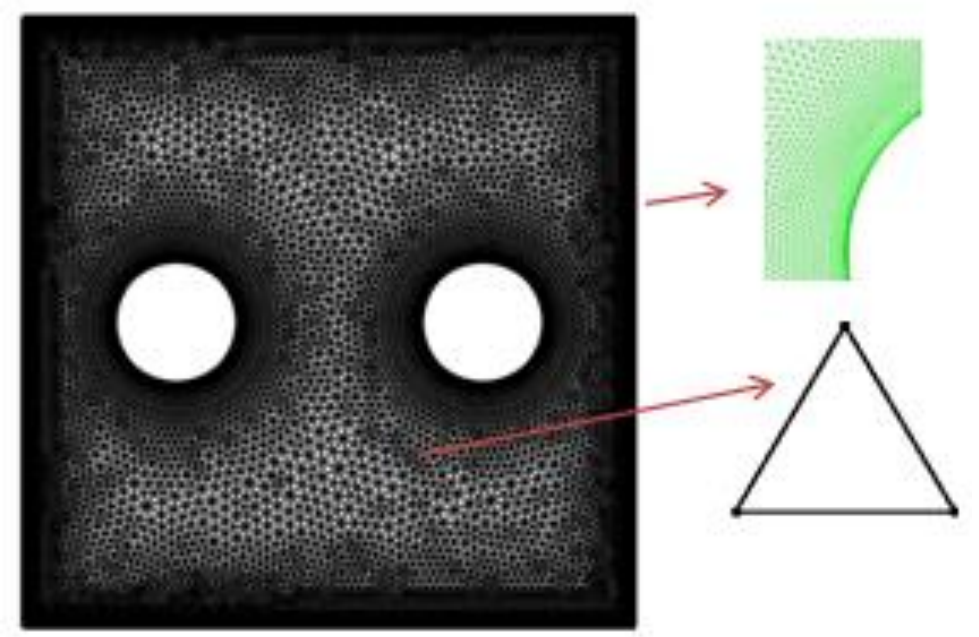

Figure (2): Triangular mesh element at $\mathrm{D}=0.2$

As illustrated in Figure (2), a Triangular structured mesh is generated to resolve this problem. For analyzing the effect of grid size on results and getting suitable results with minimum computational time and higher accuracy selection, a grid-independent performance has been used to test the average Nusselt number for several predefined mesh grids of different sizes at $\mathrm{Ri}=10$, $\mathrm{D}=0.3, \Omega=-6000, \Phi=0.06$ as shown in Table 2 . The numerical results have shown that the Nusselt number has a very small with variation of mesh elements (27400) with the mesh elements (22418) and is normally stable compared with other meshes. Therefore, the mesh (22418) has been adopted for all cases in this study. 


\begin{tabular}{|c|c|c|c|}
\hline \multicolumn{4}{|c|}{ Table 2. average Nusselt number for each mesh size at $(\mathrm{Ri}=10, \mathrm{D}=0.3, \Omega=-6000, \Phi=0.06)$} \\
\hline No. & Mesh elements & $\overline{N u}$ & Error \%100 \\
\hline 1 & 728 & 6.972 & 1.72 \\
\hline 2 & 1332 & 7.094 & 0.65 \\
\hline 3 & 1694 & 7.14 & 0.44 \\
\hline 4 & 2498 & 7.172 & 0.28 \\
\hline 5 & 7768 & 7.192 & 0.13 \\
\hline 6 & 22418 & 7.201 & 0.03 \\
\hline 7 & 27400 & 7.203 & \\
\hline
\end{tabular}

To validate the computational code used in this research is verified to provide the accuracy for the numerical results .To study a heat transfer by mixed convection inside enclosure containing a rotating cylinder filled with (Cu-Water) nanofluids, the investigation of more than one case has been conducted and compared with previous studies. The first validation of mixed convection has been conducted using the average Nusselt number for the current study compared with Roslan et.al [7].For different concentration of nanoparticles at $\left(\mathrm{Ra}=10^{5}, \Omega=100, \operatorname{Pr}=0.2\right)$ as shown in Table 3 , another validation has been conducted through stream function lines and isotherm lines for different rotational velocity at $\left(\operatorname{Ra}=10^{5}, \Phi=0.05, \operatorname{Pr}=0.2\right)$ as shown in figure (3).

Table 3. Comparison between the current work with Roslan et.al [7] in the average Nusselt number with ( $\Phi)$ of $\left(\mathrm{Ra}=10^{5}\right.$,

$$
\Omega=100, \operatorname{Pr}=0.2 \text { ) }
$$

\begin{tabular}{|c|c|c|c|c|}
\hline Rayleigh number (Ra) & $\Phi$ & Present work & Roslan.et.al & Error $100 \%$ \\
\hline \multirow{3}{*}{$10^{5}$} & 0 & 4.7594 & 4.7553 & 0.0344 \\
\cline { 2 - 5 } & 0.01 & 4.8145 & 4.8104 & 0.0851 \\
\cline { 2 - 5 } & 0.04 & 4.9736 & 4.9692 & 0.0885 \\
\hline
\end{tabular}

\section{Stream function $(\Psi)$}

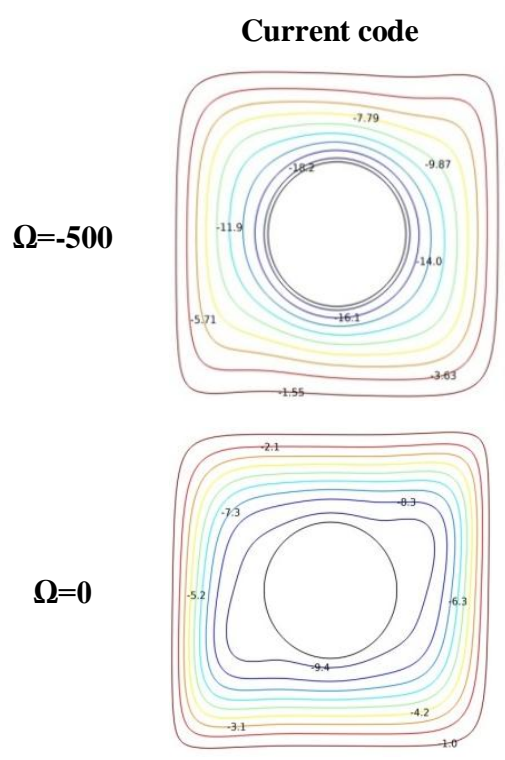

Roslan.et.al
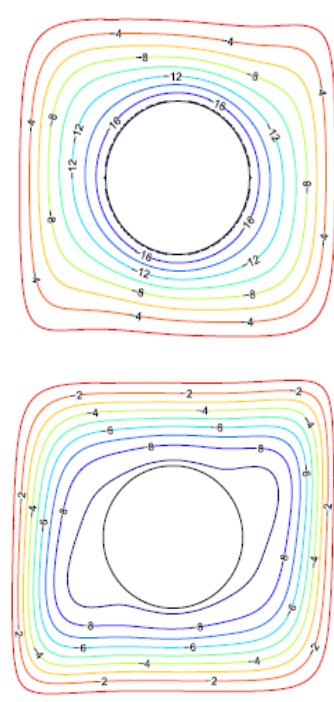

\section{Isotherms line $(\theta)$}

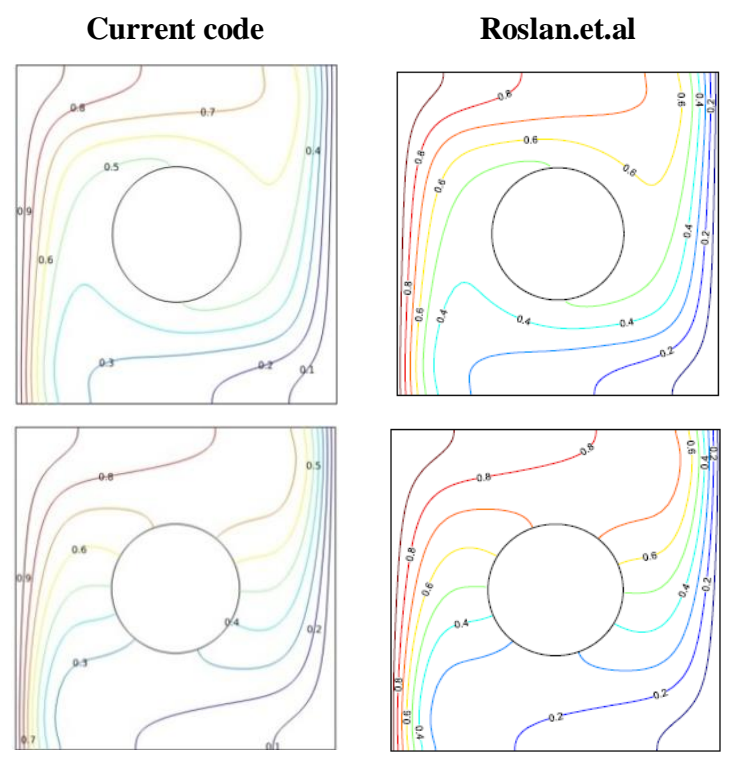



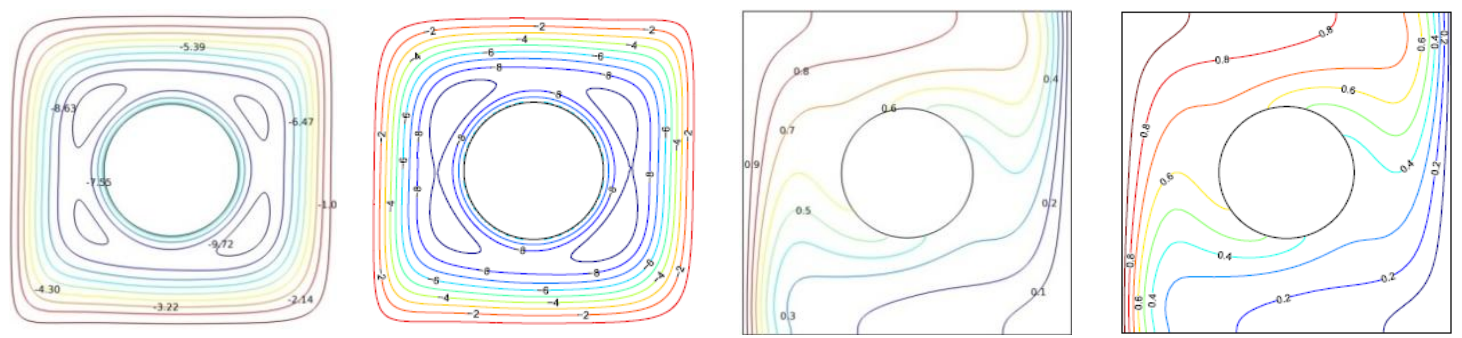

Figure (3): Comparison between the present code and that of $\operatorname{Roslan}$ et al. [7] $\operatorname{For}\left(\operatorname{Ra}=10^{5}, \Phi=0.05, R=0.2\right)$

\section{RESULTS AND DISCUSSIONS}

The current study has focused on mixed convection heat transfer of two-dimensional square enclosure containing pair rotating circular cylinder filled with (Cu-Water) nanofluid having the left cylinder at constant cold temperature and the right cylinder at a hot constant temperature while all other enclosure walls are isolated, the cylinders rotating in the same direction with same angular velocities. Numerical simulations have been presented for different ranges based on the dimensionless parameters of angular velocity $(0 \leq \Omega \leq-10000)$, solid volume fraction, $(0 \leq \Phi \leq 0.6)$, Richardson number, $(0.1 \leq \mathrm{Ri} \leq 10)$, the diameter of rotating cylinder, $(0.2 \leq \mathrm{D} \leq 0.4)$, which is based on the length of the square enclosure .The assessed numerical results have been presented using dimensionless average Nusselt number and plotted in terms of visualization, stream function $(\Psi)$, isotherms line $(\theta)$.

\subsection{Effect of Angular rotational velocity}

Figure (4) illustrates the influence of angular velocity of cold and hot cylinder on stream function line and isotherms line at $\mathrm{Ri}=10, \Phi=0.05$ and $\mathrm{D}=0.3$. The effect of the angular rotation velocity of the two cylinders $(\Omega)$ has been studied at $0,-3000,-6000$ and $-10,000$. The negative signal represents the rotational of the two cylinders clockwise direction. The left column refers to stream functions. when the angular rotation speed $\Omega=0$, it means that the two cylinders are at static state, fluid movement is in the form of small swirls through natural convection only and through buoyancy force. It can be seen that the hot cylinder in the right position and cold cylinder in the left position make the swirls rotate in the counter-clockwise direction. At $\Omega=-3000$, angular rotation velocity of the two cylinders increases, the speed of cylinder contributes to increase the circulation of flow intensity by increasing the size of the swirls at the top and bottom of the middle distance between the cylinders and the horizontal enclosure walls when compared to the previous situation $\Omega=0$, due to shear stress. At $\Omega=-6000$, an increase has been observed in the values of the stream function being as high as possible on the surface of the two cylinder, furthermore, there has been an increase in the size of the main and secondary swirls near the horizontal enclosure walls in a counter clockwise direction due to the buoyancy force is greater than shear stress force. At $\Omega=-10000$, the effect of increasing rotational velocity of the two cylinders gives additional momentum to the fluid which causes increasing in the magnitude and additional change in the form of stream function lines with increasing angular rotational velocity duo to demonstrating the shear stress force. The right column illustrates that the isotherms line is further affected by the change of the angular velocity. At $\Omega=0$, the distribution of temperature line is perpendicular to the insulated enclosure walls and it is symmetrical between the two cylinders, with further increasing angular rotational velocity at $\Omega=-3000$; the deflection of isotherms increases and the isotherms line becomes more stratified due to the strengthening of forced convection effects. At $\Omega=-6000$, It has been noticed that the distribution of heat transfer has become more evident in the enclosure. Finally, at $\Omega=-10000$, it has been shown that forced convection plays a more significant role within the enclosure. As the $\Omega$ increases, noticeable changes happen in the stream function and isotherm lines of all cases due to the shear stress force and free convection mode of heat transfer becoming more substantial.

$\Omega$ $\mathbf{0}$
Stream function( $(\Psi)$

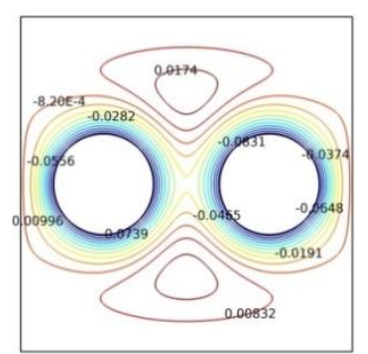

Isotherms $(\theta)$

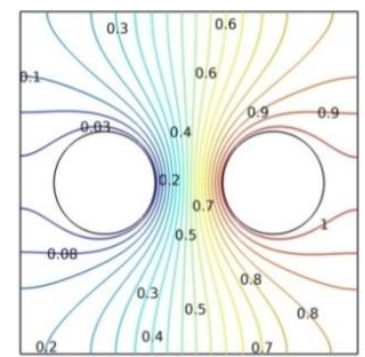


ISSN (online): 2581-3048

Volume 5, Issue 10, pp 51-64, October-2021 https://doi.org/10.47001/IRJIET/2021.510010

3000
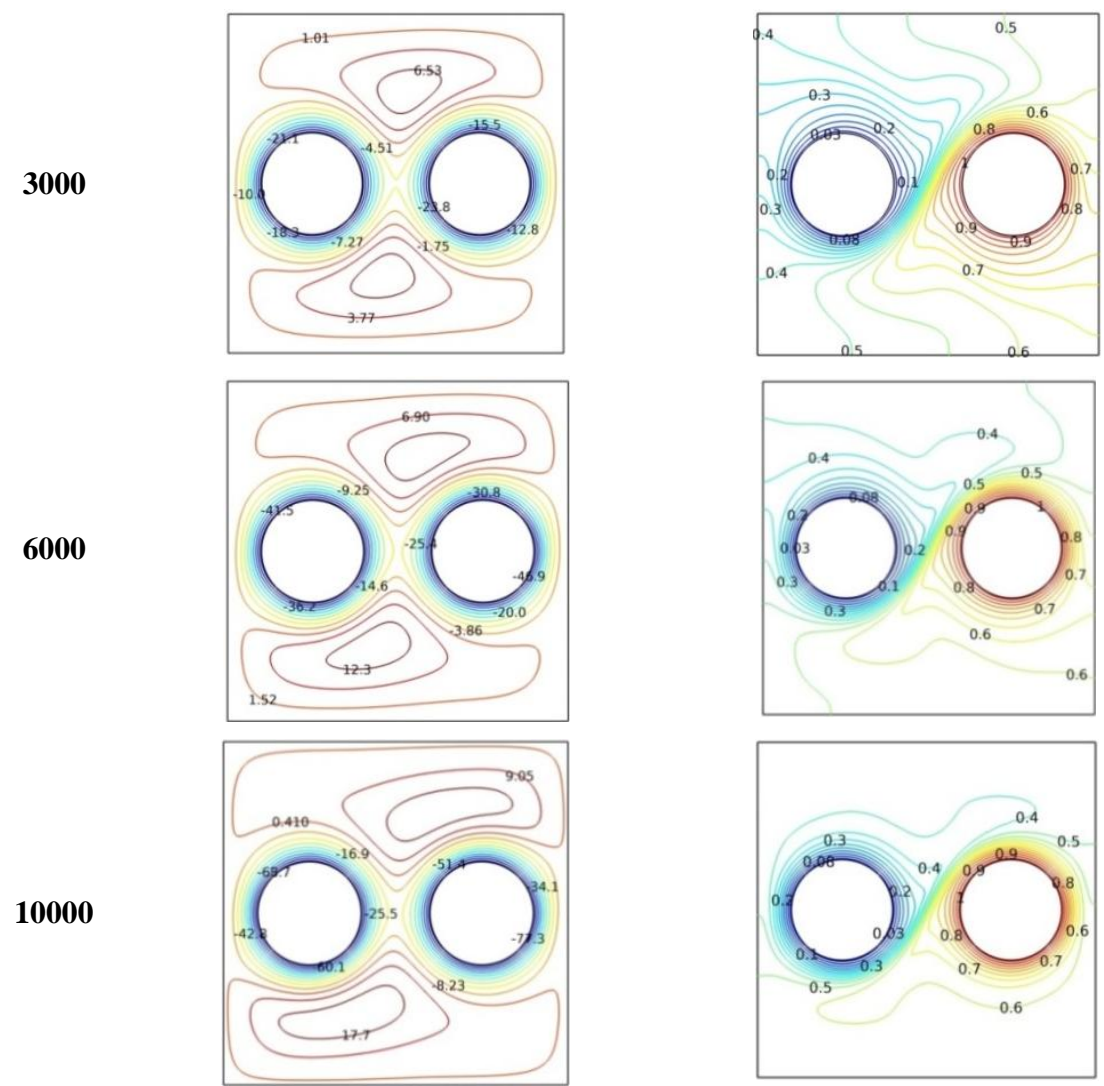

Figure (4): The variation of $\Omega$ on isotherms and stream function at

$(\mathrm{Ri}=10, \mathrm{D}=\mathbf{0 . 3}, \Phi=\mathbf{0 . 0 5})$

\subsection{The effect of nanoparticle concentration}

Figure (5) illustrates the influence of nanoparticle concentration $(\Phi)$ on mixed convection heat transfer inside enclosure through stream function line and isotherms line at constant $\mathrm{Ri}=0.1, \Omega=-10000$ and $\mathrm{D}=0.4$. The left column refers to the flow of fluid taking place in the space between the two cylinders and the enclosure walls. The increasing of nanoparticle concentration has been from 0 to 0.06 , and the two cylinders have rotated in clockwise direction. As can be seen, the flow field rotate in same direction near the cylinders surface as rotating clockwise direction while in all other region, the flow rotates in counter clockwise direction. This is due to the increase of viscosity and free convection, also, the maximum value of $|\Psi|$ obtained at the cylinder surface $\left|\Psi_{\text {Max }}\right|=60.9$ at $\Phi=0.06$, compared with $\left|\Psi_{\text {Max }}\right|=60.5$ at $\Phi=0$. The reason behind the increase in stream function with increasing of nanoparticle concentration is that the thermal conductivity of nanofluid will rise leading to increase the kinamatic energy and give increase in the stream function.

$\Phi$

0
Stream function( $(\Psi)$

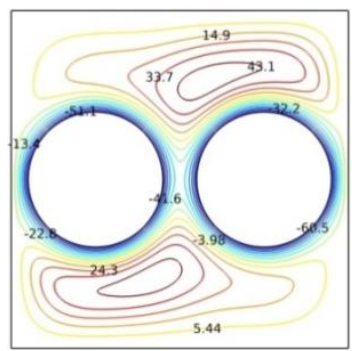

Isotherms $(\theta)$

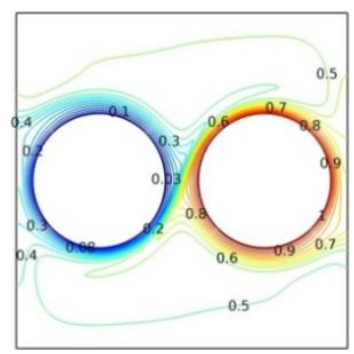


ISSN (online): 2581-3048

Volume 5, Issue 10, pp 51-64, October-2021 https://doi.org/10.47001/IRJIET/2021.510010

0.02
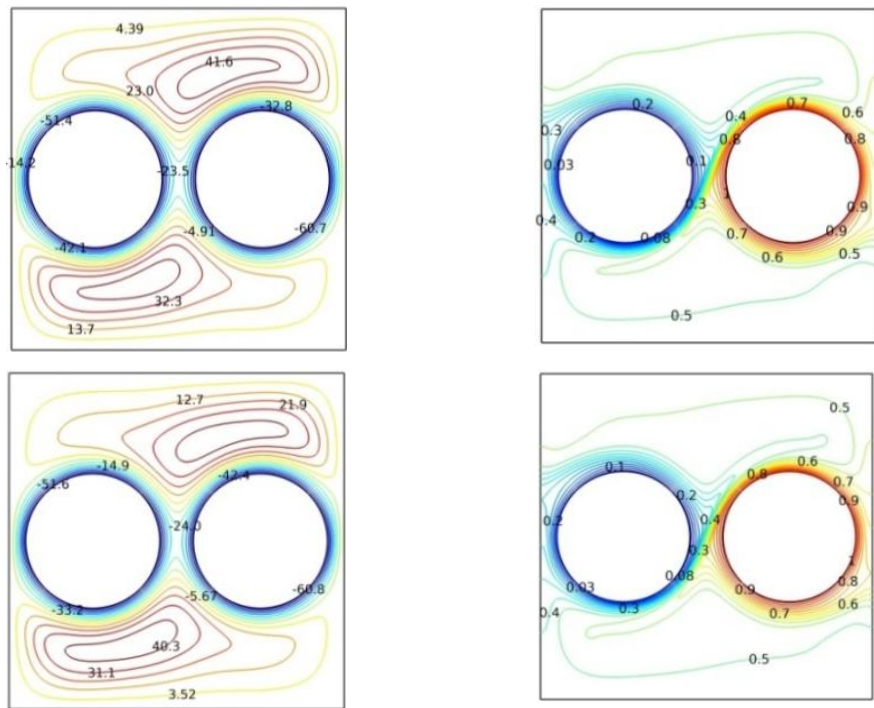

0.04
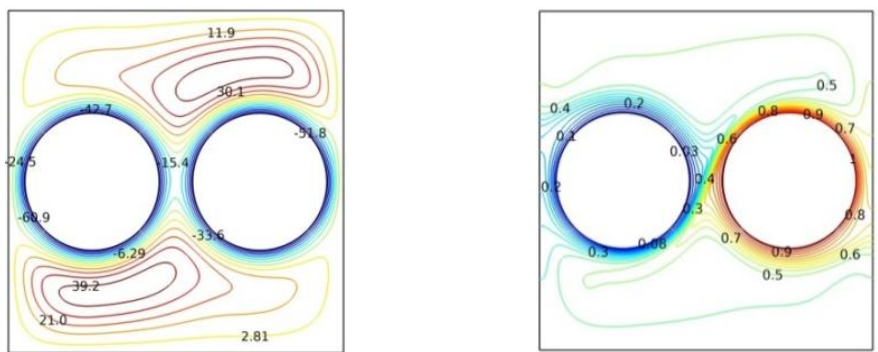

Figure (5): The effect of $\Phi$ on isotherms and stream function at

$(\mathrm{Ri}=0.1, \mathrm{D}=0.4, \Omega=-10000)$

\subsection{The effect of change the diameter of the two cylinders}

Figure (6) shows the influence of various diameter of the two cylinders (D) on the distribution of stream function line and isotherms at constant $\mathrm{Ri}=0.1, \Omega=-5000$, and $\Phi=0.01$. As can be seen in figure (6), the diameter of the two cylinders is $0.2,0.3$, and 0.4 .The column in the left side, refers to the influence of various diameter on the fluid flow, where the flow of fluid near the cylinders surface is in clockwise direction due to rotating force caused by shear stress while the flow of fluid in the other region inside enclosure movement is in the counter clockwise direction because of free convection. Therefore, the fluid rises from the right hot cylinder to the upper insulated wall and then to the left wall to complete cycle to the bottom of the cold cylinder .In the case of $\mathrm{D}=0.2$, the strength of flow swirls is much smaller and the maximum value of the stream function is noticed at the swirls $\Psi_{\text {Max }} \mid=19.2$. When the diameter of the cylinder increases to $\mathrm{D}=0.3$, it is more clear that the stream function lines are converged around the surface of the cylinders, while increase the number and size of the swirl that formed in this case. The maximum value of stream function can be noticed at the cylinder surface is $\left|\Psi_{\text {Max }}\right|=41.6$. At $\mathrm{D}=0.4$, where the stream function lines around the cylinders is more converged in addition to an increase in the number and size of the main and secondary swirls. Despite of that, the value of the maximum stream function is decreased to $\left|\Psi_{\text {Max }}\right|=29.8$.This is due to the increased diameter, the space will be narrow between the inner walls of the enclosure and the surface of the cylinders will be obstruct the movement of liquids.

D

0.2
Stream function( $(\Psi)$

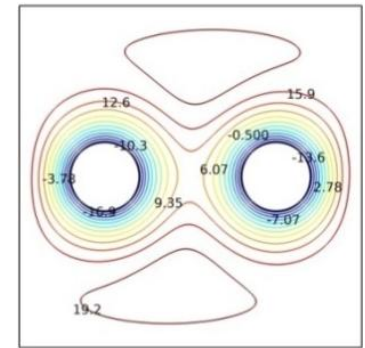

Isotherms $(\theta)$

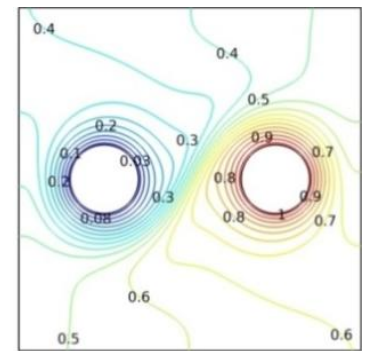


ISSN (online): 2581-3048

Volume 5, Issue 10, pp 51-64, October-2021

https://doi.org/10.47001/IRJIET/2021.510010

0.3
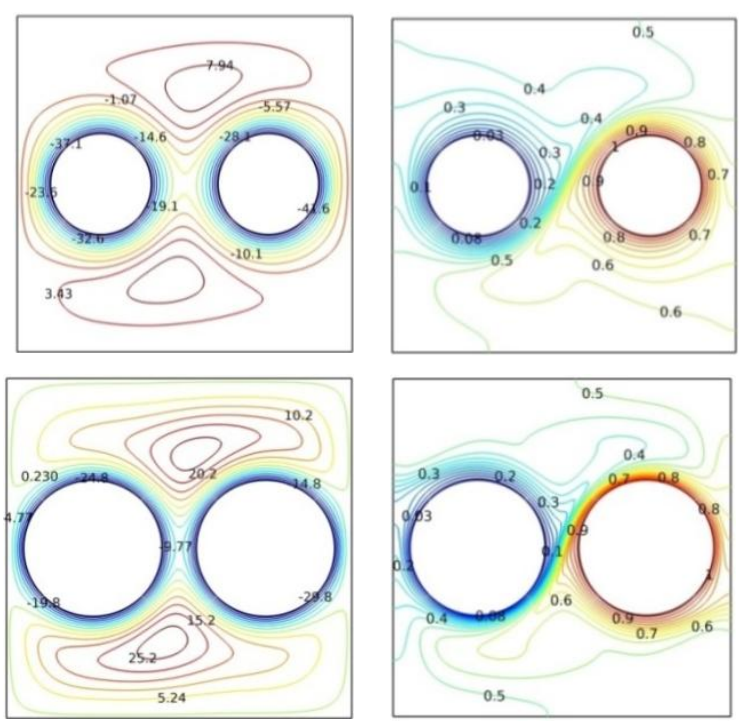

Figure (6): The Effect of $D$ on isotherms and stream function at

$(\mathrm{Ri}=0.1, \Omega=-5000, \Phi=0.01)$

The isotherms line is also affected by various diameters. As shown in the right column, the deployment of isotherms line is spread vertically on the insider enclosure and around the cylinders at $\mathrm{D}=0.2$, while at $\mathrm{D}=0.3$, the temperature gradient increases around the cold and hot cylinders and decreases from the horizontal insulated walls. More temperature gradient has also been seen around cylinders at $\mathrm{D}=0.4$. This is an indication of improved heat transfer due to the increased surface area of the hot and cold cylinders and the convergence of the distance between the two cylinders.

\subsection{Richardson number effect}

Figure (7) illustrates stream lines and isotherm lines at different Richardson number (Ri) on fluid flow and heat transfer for (Cu-Water) nanofluid at $\Omega=-4000, \Phi=0.03$, and $\mathrm{D}=0.2$. From the figure, it can be observed that the Richardson number (Ri) changes in three different values $0.1,1$ and 10 , with rotating cylinder clockwise direction. At $\mathrm{Ri}=0.1$, it can be noticed that there are two small counter clockwise direction swirls inside the upper and lower side of enclosure and the fluid flow in clockwise direction around the hot and cold cylinders despite that the value of maximum stream function is small on the surface of the cylinders but it is maximum at the swirls $\left|\Psi_{\text {Max }}\right|=15.9$. Due to small diameter with low Richardson's number, so the effect of rotational force will be near the cylinder surface just. When $\mathrm{Ri}=1$, the size of swirls are increased and the maximum stream function decreases to $\left|\Psi_{\text {Max }}\right|=15.7$ because bouncy and shear force may act in the same in a contrary way. As Richardson's number increases to $\mathrm{Ri}=10$, it has been observed that the increase in the size and number of swirls is within the cavity, while the value of the stream function has decreased more to reach $\left|\Psi_{\text {Max }}\right|=15.2$. The reason behind that is the dominance of bouncy force only. The right columns show that the temperature gradient also affected by different values of Richardson number. At $\mathrm{Ri}=0.1$, the high density of isotherms line around the cylinders and the perpendicular isotherms line on the enclosure walls has been little because of strong conduction.

$\mathbf{R i}$

0.1
Stream function( $(\Psi)$

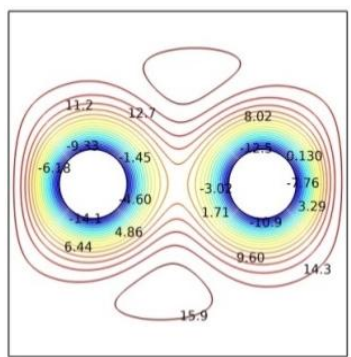

Isotherms $(\theta)$

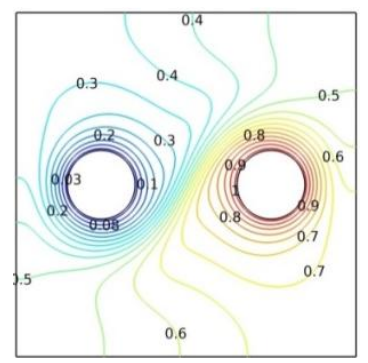


ISSN (online): 2581-3048

Volume 5, Issue 10, pp 51-64, October-2021

https://doi.org/10.47001/IRJIET/2021.510010

1
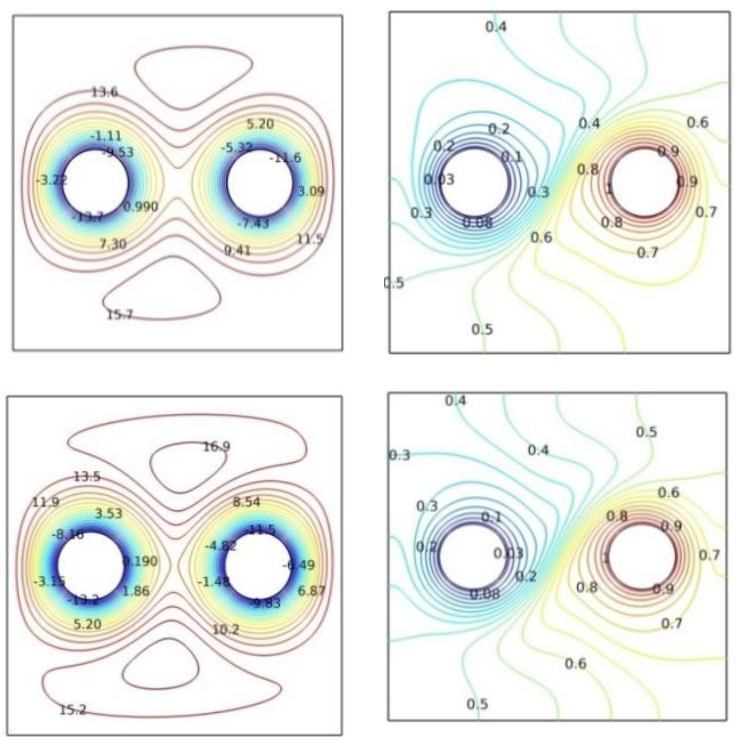

Figure (7): The variation of $\mathrm{Ri}$ on isotherms and stream functions at $(\mathrm{D}=\mathbf{0 . 2}, \Omega=-4000, \Phi=0.03)$

\subsection{Effect of variable parameters on Nusselt number}

At the beginning, it is worth pointing out that the relationship between the Grash of number and Reynolds number reveals the importance of natural and forced convection in the mixed convection case. Therefore, the combined effects of two different types of heat convection have been observed for a range of current investigations on the heat transfer indicator. For discussing the average Nusselt number in detail, Figure (8) depicts the change in the angular rotational velocity on average Nusselt number $(\overline{\mathrm{Nu}})$ of different cylinder size at, $\Phi=0.05$, and $\mathrm{Ri}=0.1$. When the angular rotational velocity $\Omega=0$, it is clear that the average Nusselt number is lower in all the diameters and the reason is that the presence of the two fixed cylinders in the middle of the enclosure constitutes an obstacle to the flow of fluid and thus reduces the rate of heat transfer of natural convection, the rotation of the two cylinders has a significant impact on improved heat transfer performance. This is because the angled rotational velocity increases the flow circulation, leading to increased heat transfer due to the effect of forced convection, it can also be noted that the highest average Nusselt number obtainable is $\overline{\mathrm{Nu}}=18$ at $\mathrm{Ri}=0.1, \Phi=0.05, \mathrm{D}=0.4, \Omega=-10000$, Because the gap between the two cylinders together and with the inner walls of the cavity is small, therefore the rotation of fluid (the speed of vortexes) upper and lower cylinders is exposed to a high temperature difference between the largest area of the hot surface and the cold surface from one side with the thermally isolated surface on the other, leading to the best heat transfer as a result of forced convection .The rate of improvement in heat transfer is $(75.17 \%)$ for the average Nusselt number at angular rotational velocity $\Omega=-10,000$, when compared to $\Omega=0$, at fixed position.

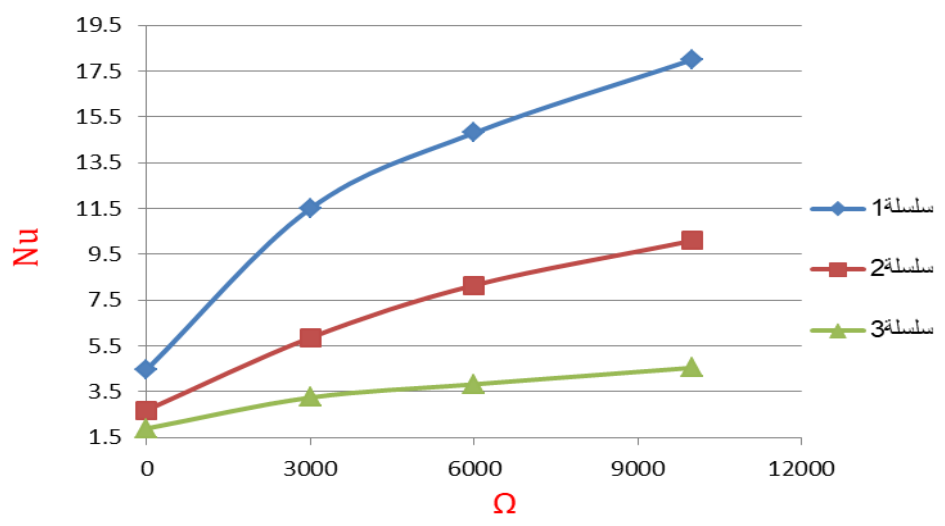

Figure (8): The variation of $\overline{\mathrm{Nu}}$ for different diameter with angular rotational velocity at $(\mathrm{Ri}=\mathbf{0 . 1}, \Phi=0.05)$

The effect of the nanoparticle volume fraction concentration on the average Nusselt number is shown in Figure (9) which depicts the different concentration of $\Phi$, and different diameters, at $\mathrm{Ri}=10, \Omega=-10000$. The figure shows that increasing 
ISSN (online): 2581-3048

Volume 5, Issue 10, pp 51-64, October-2021

https://doi.org/10.47001/IRJIET/2021.510010

concentration of nanoparticles increases the average Nusselt number of different diameters due to increases in the thermal conductivity of nanofluid and thus resulting improved heat transfer between the two surface of the hot and cold cylinders. It can also be noted that the highest value that can be obtained for the average Nusselt number at the highest concentration is $\overline{\mathrm{Nu}}=$ 18.11 at $\Phi=0.06, \Omega=-10000, \mathrm{D}=0.4$ and $\mathrm{Ri}=10$. And the Maximum ratio of the average Nusselt number that can be obtained is $15 \%$ by $\Phi=0.06$, compared to the one at $\Phi=0$ with fixed $\Omega=-10000, \mathrm{D}=0.4$, and $\mathrm{Ri}=10$.

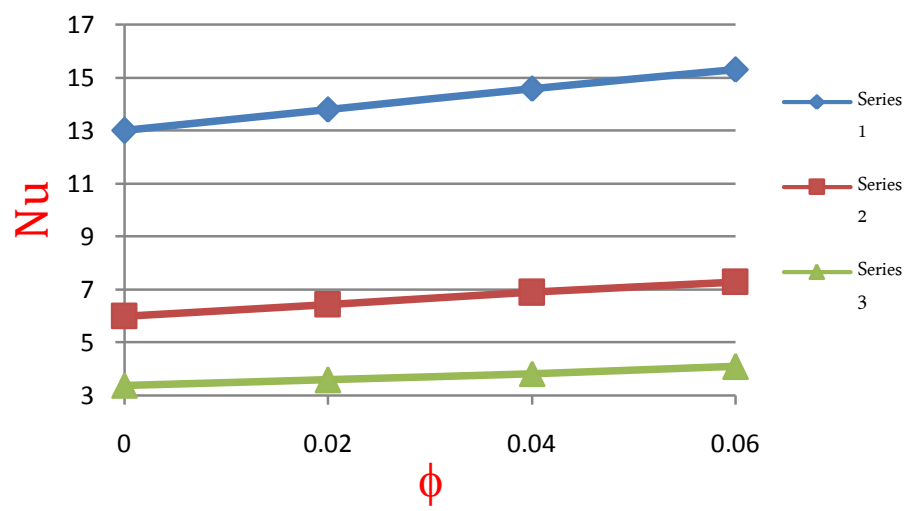

Figure (9): The variation of $\overline{\mathrm{Nu}}$ for different diameter with concentration of nanoparticles at $(\mathrm{Ri}=10, \Omega=-\mathbf{1 0 0 0 0})$

Figure (10) Demonstrates the impact of the average Nusselt number of different values of Richardson's number (Ri), and diameter at $\Phi=0.03$, and $\Omega=-8000$. At Richardson's number 0.1 , the rate of heat transfer is high due to the effect of forced convection, while the rate of heat transfer decreases as Richardson's number increases and is as minimum as possible at $\mathrm{Ri}=10$ because natural convection is the prevailing load. In brief, when Richardson's number increases it leads to a decrease in the value of the average Nusselt number. However, the value of the average Nusselt number increases with the diameter. The reason is that the increase in the diameter of the cylinders means there is a small gap between the surface of the cold and hot cylinders and the inner walls of the enclosure, and therefore the flow of fluid is very large and confined in the narrow area up and down the cylinders, and this leads to an improvement in the heat transfer. The percentage decrement of the average Nusselt number between the two cases is $25.4 \%$ at Richardson number values of 0.1 and 10 for fixed $\Omega=-8000, \Phi=0.03, D=0.3$, the rate of decline is a result of the transition from forced to natural convection.

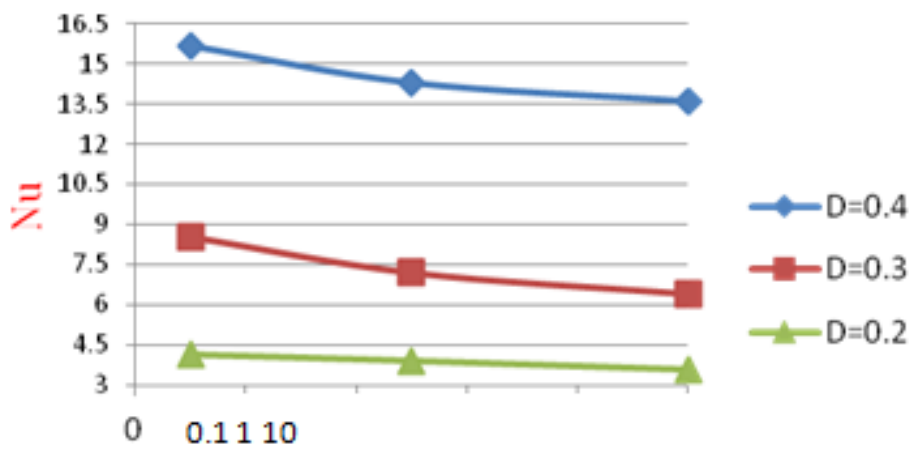

$\mathrm{Ri}$

Figure (10): The variation of $\overline{\mathrm{Nu}}$ of different diameter with Richardson number at $(\Phi=0.03, \Omega=8000)$

\section{CONCLUSIONS}

In the current study, the use of two rotating cylinders with various range of parameters for enhancing the mixed convection heat transfer inside equare enclosure filler with nanofluid is numerically simulated.A commercial code has been used to solve the problem depend on the finite element method, the effect of Richardson number $(0.1 \leq \mathrm{Ri} \leq 10)$, concentration of nanoparticles $(0 \leq$ $\Phi \leq 0.6) \%$, angular rotational velocity $(0 \leq \Omega \leq-10000)$, and diameters $(0.2 \leq \mathrm{D} \leq 0.4)$, on the heat transfer and fluid flow apparent is studied. The results showed that: 
1. The increased in rotational speed $(\Omega)$ leads to increases in heat transfer with $75.17 \%$.

2. The increasing in the concentration of nanoparticles $(\Phi)$ leads to increases in heat transfer with $3.37 \%$.

3. The increases in diameter of the two cylinders leads to increases in heat transfer with $73.25 \%$.

4. The increases in Richardson's number leads to decreases in heat transfer with $13.37 \%$.

\section{REFERENCES}

[1] F. Garoosi , F. Hoseininejad, "Numerical study of natural and mixed convection heat transfer between differentially heated cylinders in an adiabatic enclosure filled with nanofluid" Journal of Molecular Liquids 215, 1-17, (2016).

[2] C. J. Ho, M. W. Chen, and Z. W. Li, "Numerical simulation of natural convection of nanofluid in a square enclosure: Effects due to uncertainties of viscosity and thermal conductivity," International Journal of Heat and Mass Transfer, vol. 51, no. 17-18, pp. 4506-4516, 2008.

[3] P. Ternik, and R. Rudolf, "Heat transfer enhancement for natural convection flow of water-based nanofluids in a square enclosure," International Journal of Simulation Modelling, vol. 11, no. 1, pp. 29-39, 2012.

[4] M. Jahanshahi, S. F. Hosseinizadeh, M. Alipanah, A. Dehghani, and G. R. Vakilinejad, "Numerical simulation of free convection based on experimental measured conductivity in a square cavity using Water/SiO2 nanofluid," International Communications in Heat and Mass Transfer, vol. 37, no. 6, pp. 687-694, 2010.

[5] M. Sathiyamoorthy, T. Basak, S. Roy, and I. Pop, "Steady natural convection flow in a square cavity filled with a porous medium for linearly heated side wall (s)," International Journal of Heat and Mass Transfer, vol. 50, no. 9-10, pp. 18921901, 2007.

[6] A.K. Hussein, "Numerical Prediction of Free Convection Phenomena Througha Rectangular Inclined Cavity Filled with a Porous Media," Iraqi journal of mechanical and material engineering, vol. 10, no. 1, pp. 1-21, 2010.

[7] R. Roslan , H. Saleh and I. Hashim, "Effect of rotating cylinder on heat transfer in a square enclosure filled with nanofluids", International Journal of Heat and Mass Transfer 55, 7247-7256,(2012).

[8] D. Chatterjee, S. K.Gupta and B. Mondal, "Mixed convective transport in a lid-driven cavity containing a nanofluid and a rotating circular cylinder at the center" International Communications in Heat and Mass Transfer 56, 71-78, (2014).

[9] A.I. Alsabery, E. Gedik, A. J. Chamkha and I. Hashim, "Impacts of heated rotating inner cylinder and two-phase nanofluid model on entropy generation and mixed convection in a square cavity", Journal heat and mass transfer Springer-Verlag GmbH Germany, part of Springer Nature (2019).

[10] H.Sh.Majdia, A.Abdulkadhim, A.M.Abed "Numerical Investigation of Natural convection heat transfer in a parallelogramic enclosure having an inner circular cylinder using liquid nanofluid", Frontiers in Heat and Mass Transfer (FHMT), 12, 2 (2019).

[11] Y. G. Park, M. Y. Ha, C. Choi , J. Park, "Natural convection in a square enclosure with two inner circular cylinders positioned at different vertical locations", International Journal of Heat and Mass Transfer 77 -501-518(2014).

[12] F. Selimefendigil , H.F.Oztop, "Mixed convection of ferro fluids in a lid driven cavity with two rotating cylinders", Engineering Science and Technology, an International Journal 18 439e451(2015).

[13] M. A. Ismael, Fatih Selimefendigil, \& Ali J. Chamkha, "Mixed convection in A Vertically Layered Fluid-Porous Media Enclosure with Two Inner Rotating Cylinders", Journal of Porous Media, 20(6): 491-511 (2017).

[14] F. Selimefendigil , H. F. Öztop, "Mixed convection of nanofluids in a three dimensional cavity with two adiabatic inner rotating cylinders", International Journal of Heat and Mass Transfer, 117, 331-343, (2018).

[15] M. Tahmasbi, M. Siavashi1, H. R. Abbasi and M. Akhlaghi, "Mixed convection enhancement by using optimized porous media and Nanofluid in a cavity with two rotating cylinders" Journal of Thermal Analysis and Calorimetry, 10.1007/s10973-020-09604-z, (2020).

[16] K. Khanafer, K. Vafai, M. Lightstone, "Buoyancy-driven heat transfer enhancement in a two-dimensional enclosure utilizing nanofluids," International Journal of Heat and Mass Transfer 46 3639-3653(2003).

[17] T. Wah-Yen, Y. Asako, N. A. CheSidik, G. Rui-Zher, "Governing Equations in Computational Fluid Dynamics: Derivations and A Recent Review," Progress in Energy and Environment 1, 1 - 19, (2017).

[18] S. H. Hussain, A. K. Hussein, "Mixed convection heat transfer in a differentially heated square enclosure with a conductive rotating circular cylinder at different vertical locations," International Communications in Heat and Mass Transfer 38, 263274 (2011).

[19] Young Cho, "Hydrodynamic and Heat Transfer Study of Dispersed Fluids with Submicron Metallic Oxide Particle," Experimental Heat Transfer DOI: 10.1080/08916159808946559 (1998). 
ISSN (online): 2581-3048

Volume 5, Issue 10, pp 51-64, October-2021

https://doi.org/10.47001/IRJIET/2021.510010

[20] H. Sajjadi • H. Mohammadifar• A. AmiriDelouei, "Investigation of the effect of the internal heating system position on heat transfer rateutilizing Cu/water nanofluid," https://doi.org/10.1007/s10973-019-08611-z) (2019).

[21] M. Dhahri , H. Aouinet, H. sammouda, "A new empirical correlating equation for calculating effective viscosity of nanofluids", Wiley, DOI:10.1002/htj.21445(2018).

[22] A.J. Chamkha, M. A. Ismael, "Conjugate heat transfer in a porous cavity filled with nanofluids and heated by a triangular thick wall," International Journal of Thermal Sciences 67, 135e151 (2013).

[23] I.Gonçalves, R. Souza, G. Coutinho, J. Miranda, A. Moita, "Thermal Conductivity of Nanofluids: A Review on Prediction Models, Controversies and Challenges”, MDPI, applied sciences, Appl. Sci, $11,2525$. https://doi.org/10.3390/app11062525 (2021).

[24] A.Salih, "Streamfunction-Vorticity Formulation", Indian Institute of Space Science and Technology, Thiruvananthapuram (2013).

[25] Y.A.CANGEL, "HEAT TRANSFER", A practical Approach, hand book, (2002).

[26] T.R. Taha, "An Introduction to Parallel Computational Fluid Dynamics", Nova Science Publishers Commack, N.Y. ISBN $1-56072-354-8(1997)$.

\section{Citation of this Article:}

Farhan A.I., Ziad M.Al-Makhyoul, "Mixed Convection of Heat Transfer around Rotating Cylinders inside Enclosure Filled with Nano Fluid" Published in International Research Journal of Innovations in Engineering and Technology - IRJIET, Volume 5, Issue 10, pp 51-64, October 2021. Article DOI https://doi.org/10.47001/IRJIET/2021.510010 